\title{
25 Research Soure \\ Determinants of consistent condom use among Filipino women: Results from the 2017 Philippine National Demographic and Health Survey
}

\section{Veincent Christian Pepito ( $\sim$ vpepito@ateneo.edu )}

Ateneo de Manila University Ateneo School of Medicine and Public Health https://orcid.org/0000-0001-5391-3784

Arianna Maever L Amit

Ateneo de Manila University Ateneo School of Medicine and Public Health

Clinton S Tang

Ateneo de Manila University Ateneo School of Medicine and Public Health

Ryan Gabriel C Molen

Ateneo de Manila University Ateneo School of Medicine and Public Health

Luis Miguel B Co

Ateneo de Manila University Ateneo School of Medicine and Public Health

Neil Andrew Kiamco Aliazas

Ateneo de Manila University Ateneo School of Medicine and Public Health

Sarah J De Los Reyes

Ateneo de Manila University Ateneo School of Medicine and Public Health

Lourdes Bernadette Sumpaico Tanchanco

Ateneo de Manila University Ateneo School of Medicine and Public Health

\section{Research Article}

Keywords: Consistent condom use, unwanted pregnancy and sexually transmitted infections, high fertility rate

Posted Date: June 14th, 2021

DOI: https://doi.org/10.21203/rs.3.rs-588095/v1

License: (1) This work is licensed under a Creative Commons Attribution 4.0 International License. Read Full License 


\section{Abstract}

Background: Consistent condom use had been perennially low in the Philippines, despite being a tested and proven public health intervention to promote unwanted pregnancy and sexually transmitted infections. Considering the high fertility rate, teenage pregnancy rate, and the rapidly increasing incidence of HIV in the country, we identify the determinants of consistent condom use in the country.

Methods: We used data from the individual recode of the 2017 Philippine National Demographic and Health Survey. We used logistic regression for survey data to identify factors associated with consistent condom use.

Results: Out of 25,074 respondents, only 261 (1.13\%) have used condoms consistently with their most recent partner. Reach of information and education campaigns on contraceptive use via different media ranged from $62 \%$ via television to $7 \%$ via SMS. After adjusting for confounders, we find that respondents who can ask their partners to use a condom during intercourse have 6.31 times higher odds $(95 \% \mathrm{Cl}: 2.08,19.16)$ of using condoms consistently as compared to respondents who are unable to do so. We also find that current non-users of any form of contraceptive method but intend to use it later have 8.94 times greater odds (95\% Confidence Interval (Cl): $2.41,33.18)$ and those who use modern contraceptive methods have 59.67 times greater odds (95\% Cl: 21.14-168.47) of being a consistent condom user as compared to non-users of any contraceptive method who do not intend to use it later.

Conclusions: The low percentage of those who use condoms consistently, together with the low reach of information and education campaigns highlight the need to further intensify these efforts especially in older women beyond the reach of school-based sex education interventions. Interventions to improve sexual agency, such as improving sex education, living conditions, and social support should also be implemented to increase the prevalence of consistent condom use in the Philippines.

\section{Plain English Summary}

The Philippines is beset with the triple burden of high teenage pregnancy, high incidence of HIV, and high fertility rates. Among the most cost-effective public health interventions to address this triple burden is consistent condom use. However, consistent condom use in the country had been exceptionally low. There are also very scant previous studies on the factors associated with consistent condom use in the Philippine general population. Thus, we used a nationally representative survey to assess the factors associated with consistent condom use among Filipino women aged $15-49$. In the survey, only $1.13 \%$ of the respondents have consistently used condoms with their most recent partners. Reach of information and education campaigns on contraceptive use via different media ranged from $62 \%$ via television to $7 \%$ via SMS. After controlling for the effect of other variables, sexual agency, measured by the respondent's ability to ask their partners to use condoms during sexual intercourse, was found to be strongly associated with consistent condom use. These findings highlight the need for interventions to promote sexual agency among women by improving sex education, living conditions, and social support for younger women. For older women, there is a need for an intensified information and education campaign to promote sexual agency and consistent condom use to address the triple burden of high teenage pregnancy, high incidence of HIV and high fertility rates in the Philippines.

\section{Introduction}

High fertility rates, high teenage pregnancy rates, and increasing HIV incidence are three of the most pressing reproductive health issues in the Philippines today. As of 2019, the Philippines has a total fertility rate of 2.98, which is the second highest in Southeast Asia, and is much higher than the global average of 2.31 [1]. Similarly, the country has a teenage pregnancy rate of $9 \%$ as of 2017, which is also one of the highest in Southeast Asia, and has barely changed for the 10 years preceding it [2]. Lastly, the country is also one of the few countries in the world where the incidence of HIV is rapidly increasing [3]. The only health intervention that can address these three issues simultaneously is consistent condom use [4,5].

Despite the established cost-effectiveness of condoms in preventing unwanted pregnancies and sexually transmitted infections (STIs), condom use has always been low in the Philippines. According to the 2017 Philippine National Demographic and Health Survey (NDHS), only $2 \%$ of currently married women and $3 \%$ of sexually active unmarried women have male partners who have ever used condoms [6]. A systematic review of condom use in the Philippines found 27 studies involving different populations in selected areas throughout the country [7]. The same review have found that the range of prevalence of consistent condom use ranged from $3 \%$ among men who have sex with men in Metro Manila to 74\% among female sex workers (FSW) in lloilo City [7-9]. The same review found that facilitators of condom use in the country include being single, frequent STI tests, greater educational attainment, higher monthly wage, higher perceived HIV risk, engaging with FSW, knowledge of HIV, longer employment period, personal decision, positive attitudes on 
condom use, HIV status, prevention of pregnancies and STIs, peer influence, type of work establishment and workplace support, access to health facilities and merchandise stores, health provider engagement, and government policies and regulations. On the other hand, barriers to condom use include perceived discomfort and displeasure, fear, marital status, lack of condoms, low knowledge, lack of money, low perceived HIV risk, stigma, substance abuse, use of other contraceptive methods, coercion, miscommunication and misinformation, preference of partners and peers, lack of sex education, discreet placements of condoms in stores and distance to stores, religion, HIV testing requirement, and high price of condoms [7-29]. However, data for most of these studies were collected before the enactment of the Reproductive Health Law and the Executive Order No. 12 in 2012 and 2017, respectively, which both aim to attain and sustain zero unmet need for modern family planning $[30,31]$. Moreover, all of the studies have a limited geographic and demographic scope, and only two of them have focused on consistent condom use [12,14].

In other countries, similar determinants were also found to be associated with consistent condom use [32]. Behavioral skills were found to be associated with consistent condom use among college students in China [33]. In another study involving female sex workers in China, environmental and structural support, perceived benefits and protection, and high safe sex self-efficacy were found to be associated with consistent condom use [34]. In a study involving people living with HIV in Ethiopia, rural residence and partner influence were found to be associated with consistent condom use [35]. Lastly, in a study in Nigeria, condom self-efficacy, having discussions on HIV/STIs with partner, knowing HIV status of partner, and living in areas with high HIV prevalence, and number of sexual partners were associated with consistent condom use. Trust, unavailability of condoms, dislike of condoms, and perceived reduction in sexual pleasure were the main reasons for inconsistent condom use [5].

To address the dearth of nationally representative studies on consistent condom use which could also serve as basis for further refinements to newer policies on reproductive health, this paper aims to examine the determinants of consistent condom use among Filipino women aged 15-49.

\section{Methods}

Study population and sampling method

The 2017 Philippine NDHS is a nationally representative survey whose primary objective is to provide up-to-date estimates of basic demographic and health indicators. The survey utilized a two-stage stratified design utilizing the Master Sampling Frame designed by the Philippine Statistics Authority. The strata used were 117 major sampling domains in the country (81 provinces, 33 highly urbanized cities and 3 special areas). The first stage sampling involved the systematic selection of 1,250 primary sampling units throughout the entire Philippines. Such primary sampling units can be barangays (Philippine equivalent of village), a portion of a large barangay or two or more adjacent small barangays. Once these primary sampling units were selected, either 20 or 26 housing units were systematically random sampled. Non-replacement sampling was utilized to prevent bias. Survey weights were then computed. All women aged 15-49 years old who were either permanent residents of the selected households or visitors who stayed in the households the night before the survey were eligible to be interviewed. Other details of the sampling method utilized by the survey is available in its published manuscript [6].

\section{Data collection, definition of variables, and data management}

Two questionnaires administered using tablet computers by trained field interviewers were used for the 2017 NDHS. The questionnaires were translated to six local languages commonly spoken throughout the Philippines: Tagalog, Cebuano, llokano, Bikol, Hiligaynon, and Waray and were then pre-tested. Actual data collection was done on August 14 to October 27, 2017. Data processing began shortly after initiation of data collection, and a clean dataset was prepared by late 2017 [6]. For this analysis, we will use the Individual Recode dataset of the 2017 Philippine NDHS.

The survey collected data on socio-demographic variables, fertility levels and preferences, awareness and use of family planning methods, breastfeeding, maternal and child health, child mortality, awareness and behavior regarding HIV/AIDS, women's empowerment, domestic violence, and other health-related issues [6]. For this analysis, however, we will only make use of data on sociodemographic, awareness and use of family planning methods, and awareness and behaviors regarding HIV/AIDS. Specifically, the outcome variable for this analysis is consistent condom use, defined as the self-reported usage of male/female condom in every sexual encounter of the respondent with her most recent partner in the last 12 months. For this variable, we combined the categories for "did not use condom in last sexual intercourse" and "used condom inconsistently" as the no outcome group, while we considered those who used condoms consistently as having the outcome. 
From the literature, known determinants of consistent condom use in the Philippines such as educational attainment, employment, HIV knowledge, and alcohol use will be forced into the resulting regression models [12,14]. In addition to this, we will also assess the effect of variables on consistent condom use: age, wealth index, marital status, HIV testing, tobacco use, intention and usage of traditional and other modern contraceptive methods, total children ever born, husband/partner's education level, whether it is justifiable for a wife to ask husband to use condom if he has STI, agency (measured as whether the respondent can ask partner to use condom) [36], decision-maker for using contraception, reading about contraception in the internet, heard about family planning on radio, tv, newspaper/magazine, and text message, age of partner, HIV testing, and household size.

The HIV knowledge questions were aggregated from the answers of respondents on eight yes or no items from the NDHS: (a) reduce risk of getting HIV by having sex with only one partner who has no other partners; (b) reducing risk of getting HIV by always using condom; (c) can get HIV from mosquito bites; (d) can get HIV by sharing food with somebody; (e) a healthy looking person can have HIV; (f) HIV can be transmitted during pregnancy; (g) HIV can be transmitted during delivery; (h) HIV transmitted by breastfeeding. For each item a respondent gets correctly, the respondent gets one point. The points from each item were added to comprise the HIV knowledge score, thus, those who have a higher HIV knowledge score have greater HIV knowledge as compared to those who have low knowledge. We also recoded some categorical variables to ensure that each category would have sufficient respondents.

\section{Data Analysis}

All data management and analyses were carried out in Stata 14.0 IC [37] and we used a level of significance of 0.05 [38]. After data cleaning and recoding, we declared our dataset as survey data using the weighting for the entire survey as sampling weight. All our subsequent analyses are weighted, except for analyses that do not have an option for weighting. Thus, proportions, means odds ratios, and p-values, except for tests of normality and rank-sum tests, were weighted. However, we still showed the number of observations, which are unweighted. Once we declared our dataset as survey data, we ran descriptive statistics for all variables of interest. We identified the proportions and frequencies of the categories for each of our categorical variables. For our continuous variables, we described their range, distribution, and the appropriate measure of central tendency. We also described the number of respondents with missing data for each variable under study.

We then cross-tabulated the different exposure variables with our outcome variable. We note the p-values of the Pearson's chisquare test and crude odds ratios. For our continuous exposure variables, we performed either Wald test for normally distributed variables or rank-sum test for skewed variables, to assess their association with the outcome. Once we have done the cross-tabulations, we ran a correlation matrix to assess potential collinearity between variables. If variables will have a correlation coefficient of $>0.70$, one of the variables were removed from the analyses. Prior to doing multivariate analyses, we also excluded respondents with those who have missing data in any of the variables of interest by using Stata's subpop function to ensure that estimates and standard errors are computed correctly.

We used logistic regression for survey data to estimate the crude and adjusted estimates of the associations between the different exposure variables and consistent condom use. In choosing the variables to include our final model, we first categorized variables into proximal and distal risk factors. Proximal risk factors are risk factors that are closer to the outcome, while distal risk factors are risk factors that are more "upstream" and usually affect the outcome indirectly. In building our model, we first fit distal factors that are strongly associated with consistent condom use from our cross-tabulations. Once we have the distal factors in our model, we fit the proximal risk factors who were associated with the outcome in our cross-tabulations.

\section{Results}

A total of 25,074 women aged 15 to 49 years old, with a mean age of 30.14, from across the Philippines participated in the 2017 Philippine NDHS and were included in the analysis. Around $80 \%$ of the population are Roman Catholics, $42 \%$ are married, around $86 \%$ completed high school or college and $54 \%$ reportedly being employed at the time the survey was conducted. Around $51 \%$ were reported to be living in rural areas whereas $49 \%$ were found in the urban areas. Around three-fourths of respondents did not report alcohol consumption, while $95 \%$ reported tobacco consumption. With regards to HIV testing, 95\% reported never being tested for the infection despite an average score of 5 in terms of HIV knowledge test. For information regarding family planning and contraceptive knowledge, television was reportedly the most frequent primary source of information (62\%), followed by internet (37\%), radio (34\%) newspaper/magazine (20\%) and short messaging service on mobile phone (7\%). When asked about intimate relations, the average total lifetime number of sex partners in the observed population was 1.4 . Only $261(1.13 \%)$ have reported using condoms consistently with their latest sexual partner. 
Without adjusting for confounding variables, there is strong evidence that educational attainment of respondent, wealth index, current marital status, contraceptive use and intention, belief that wife is justified to ask husband to use condom if he has an STI, agency, hearing information on contraception via internet and/or television were strongly associated with consistent condom use (Table 1). In addition to the said variables, HIV knowledge, age of respondent, age of most recent partner, and total children ever born were also strongly associated with consistent condom use (Table 2).

Prior to doing multivariate analysis, we assessed for potential autocorrelation between exposure variables. In this assessment, we see autocorrelation between age of partner and age of respondent. As a result, we no longer consider age of respondent as an exposure variable as we proceed with multivariate analysis. Among the exposure variables showing evidence of association with consistent condom use, we identify educational attainment of respondent, wealth index, current marital status, and age of respondent as distal variables. Alcohol use and employment status, while not showing statistically significant relationships with the outcome in this dataset, were forced in the model as distal variables as they were found to be a determinant of the outcome in previous studies. The remaining variables showing association with the outcome variable - contraceptive use and intention, belief that wife is justified to ask husband to use condom if he has an STI, respondent's ability to ask partner to use condom, hearing information on contraception via internet and/or television, HIV knowledge, and total children ever born - were classified as proximal variables. At this point, we no longer considered the other variables in subsequent analyses. We also exclude data from respondents with missing data in any of the remaining variables of interest. As a result, we exclude some 11,791 (47.1\%) respondents, mostly those with missing data on consistent condom use or those who have not had any sexual activity yet and are left with 13,283 (52.9\%) respondents.

After adjusting for other variables in the model, we find that there is strong evidence that contraceptive use and intention, as well as agency, were the only factors that were associated with consistent condom use. Specifically, those who said that they are currently nonusers of any form of contraceptive method but intend to use later have 8.94 times greater odds (95\% Confidence Interval (Cl): 2.41, 33.18) of being a consistent condom user as compared to non-users who do not intend to use contraceptives. Users of modern forms of contraceptive methods (including male and female condoms) have 59.67 times greater odds (95\% $\mathrm{Cl}$ : $21.14,168.47)$ of being a consistent condom user as compared to non-users who do not intend to use contraceptives. Also, respondent who can ask their partner to use condom during sexual intercourse have 6.31 times higher odds ( $95 \% \mathrm{Cl}$ : $2.08,19.16)$ of using condoms consistently as compared to respondents who are unable to ask their partners to use condoms during sexual intercourse. Other variables which have shown evidence of association with consistent condom use at the univariate analysis no longer showed evidence of association with the outcome at multivariate analysis (Table 3 ).

\section{Discussion}

Despite the proven effectiveness of consistent condom use in preventing unwanted pregnancies and STIs, only $1 \%$ of the respondents use condoms consistently. This, together with the low reach of various campaigns on contraceptive use throughout different forms of media, underscore the need to strengthen sex education and promote optimal reproductive health behaviors, such as consistent condom use, in the general population. In our search for determinants, we find that educational attainment of respondent, wealth index, current marital status, contraceptive use and intention, belief that wife is justified to ask husband to use condom if he has an STI, agency, hearing information on contraception via internet and/or television, HIV knowledge, age of respondent, age of most recent partner, and total children ever born were associated with consistent condom use. However, after adjusting for other variables, only agency and contraceptive use and intention showed strong evidence of association with consistent condom use.

Sexual agency has been defined "as the strategic negotiations of an individual to situate oneself and one's choices in a social context, maintain relationships and make sense of experiences". However, because each individual has different experiences and grew up in different environments, there are structural inequalities in sexual agency [39]. A qualitative study exploring sexual agency among young women in the Philippines found that many Filipino women have avoided or have no sexual agency, explaining that their first sexual experience was succumbing to coercion or emotional pressures of being with their partners, or worse, being raped [40]. In another study involving Filipino women, low sexual agency, measured by her inability to ask a partner to use condoms during intercourse, was found to be associated with experiencing intimate partner violence. [36]. Since we find that a woman's ability to ask a partner to use condoms during intercourse is very strongly associated with consistent condom use, there should be measures to strengthen sexual agency among Filipino women. This could be done by educating and empowering them to make choices on their sexuality and reproductive health as early as puberty. The recent passage of the Philippine Reproductive Health Law, which has specific provisions for adolescent and youth reproductive health guidance and counseling, reproductive health education for adolescents, and prevention and management of reproductive health guidance and counselling, is a step in the right direction [41], but there may be a need to revisit its 
implementing rules and regulations and further strengthen its implementation considering that inconsistent condom use and teenage pregnancy is still prevalent in the country [6]. A recent paper on sexual agency advocates going beyond focusing solely on sex education interventions in promoting sexual agency. Instead, they advocate for improving living conditions, education, and social support, opining that these have greater effect on improving sexual agency than sex education interventions [42]. The association between sexual agency and consistent condom use also highlights the need for a more intensified information and education campaign to promote modern contraceptive methods, particularly consistent condom use, among older women no longer reached by school-based sex education.

Contraceptive use and intention is the other variable that showed a strong evidence of association with consistent condom use. As expected, those who said that they are using modern forms of contraception, which includes male or female condom, showed strong evidence of association with consistent condom use. This finding highlights the necessity of promoting modern forms of contraception, which have been demonstrated to be more effective in preventing unwanted pregnancies than traditional contraceptive methods [43]. Further highlighting the necessity of promoting modern forms of contraception is the exceptionally low percentage of respondents who said that they are using modern forms of contraception. However, in doing so, misperceptions on modern contraceptive methods should be addressed [43]. More importantly, a nuanced understanding of how pleasure, power, and inequalities should be considered in devising interventions to promote modern contraceptive methods [44]. The consideration on pleasure is particularly salient in the Philippine context as the perception that condoms are not comfortable to use and causes displeasure has been found to be a barrier to condom use in a previous review. The same review mentions the need for a "collaborative, culturally-sensitive, and population-specific approach to develop and implement acceptable, sustainable and successful condom use interventions" [7]. This study adds that more than just condom use, interventions should focus on promoting consistent condom use as the benefits of preventing STIs and unwanted pregnancies can only come from consistent use of condoms. More importantly, the prevention of teenage pregnancy by consistent condom use also protects women from the stigma and economic hardship brought about by teenage pregnancy.

There is strong evidence of association between current non-users of contraception who indicated that they would use contraception later, and consistent condom use, which is counter intuitive. We attribute this issue to how the question on contraception use and intention and how outcome variable was asked. The question on contraceptive use and intention deals with contraception use as absolutes - it is either the respondent uses a traditional or modern method, or if they do not use now, they are categorized to either using it later, or not at all [6]. However, there are temporary contraceptive methods such as condoms, which would mean that in practice, respondents may sometimes use these methods, and sometimes they will not. These nuances are not reflected in how the question was asked, which leads the respondent to classify herself as to what best reflects her among the choices instead of what her actual contraception use and intention is. The outcome variable is a combination of two questions - the first one asking if they had used condoms in their most recent intercourse with their most recent partner - and a follow-up question asking if they had used condoms consistently in the past 12 months. This implies that some respondents may be using condoms consistently with their most recent partner, but may not be with their other partners, hence answering that they are current non-users of contraception, and yet still get classified as using condoms consistently with their most recent partner. Alternatively, this could just be an inconsistency in how respondents report their data on contraceptive use and intention, and on condom use, which is quite common in studies using self-report data. Lastly, there may be unquantified interactions between contraception use and other variables on their joint effects on consistent condom use. A previous study demonstrated that there is interaction between condom intention and sexual communication, the latter of which was not measured in this analysis. As their analysis demonstrates, interventions to prevent unsafe sex should therefore not only focus on contraceptive intention and education, but also on sexual communications [45]. Such interventions need to be culturally appropriate and dynamic in such a way that sexual partners empower each other in the decision to consistently use modern contraceptives in a healthy, mature relationship.

While the nominal sample size was large for both univariate and multivariate analyses, the relative rarity of consistent condom use in the population (261 in the descriptive analysis and only 200 left in multivariate analyses) resulted in very wide confidence intervals, nonsignificant result for factors supposedly associated with the outcome, and residual confounding as we are constrained to select only the most powerful confounders to be included in the final model. We would have wanted to control for the effect of other known determinants of consistent condom use, such as religion and domicile, but ultimately decided against it for the sake of parsimony. Doing so would estimate another six parameters which would further destabilize our model. In addition, we have also excluded around half of respondents who have missing data for consistent condom use and/or partner variables, which potentially means selection bias due to missing data and limits the generalizability of our findings to Filipino women who currently have partners in their relationship.

\section{Conclusions}


Despite these limitations, interventions to promote consistent condom use should be implemented to address the exceptionally low prevalence of consistent condom use in the population. After adjusting for confounders, we find that women with greater sexual agency and users of contraceptive methods are more likely to use condoms consistently than non-users of modern contraceptive methods, or women with low sexual agency. This implies that interventions to improve sexual agency, such as improving sex education, living conditions, and social support might also work to increase the prevalence of consistent condom use in the population. There should also be a more intensified information and education campaign to promote modern contraceptive methods, particularly consistent condom use, for older women no longer reached by school-based sex education interventions considering that the reach of various campaigns in promoting modern contraceptive use on various media had been low. With better agency and education, we empower individuals to make responsible choices about their sexual and reproductive health, hopefully addressing the triple burden of teenage pregnancy, high fertility rate, and HIV/STIs in the country.

\section{Abbreviations}

FSW - Female Sex Workers

HIV - Human Immunodeficiency Virus

MSM - Men who have sex with men

NDHS - National Demographic and Health Survey

STI - Sexually transmitted infection

\section{Declarations}

\section{Ethics approval and consent to participate}

The study has undergone ethics approval at the Ateneo de Manila University Research Ethics Committee (Protocol ID: SMPH DATA 2020).

Consent for publication

Not applicable.

Availability of data and materials

The data for the 2017 Philippine National Demographic and Health Survey Individual Recode are available from the Demographic and Health Surveys Program Website (https://www.dhsprogram.com/data/available-datasets.cfm).

\section{Competing interest}

The authors declare no competing interests.

\section{Funding}

This study is supported by the Ateneo de Manila University Research Council Standard Grant (Grant No.: 2020-01).

Contributions

VCFP, AMLA, and LBST conceived the study. VCFP and AMLA performed the statistical analysis. VCFP, CST, NAKA, RGJM, and LMBC wrote the first draft. AMLA, SJDLR and LBST gave feedback and reviewed the drafts of the manuscript. All authors read and approved the final manuscript.

Acknowledgments

We thank the Demographic and Health Survey Program for allowing us to use their datasets to carry out this project.

\section{References}


1. Wang H, Abbas KM, Abbasifard M, Abbasi-Kangevari M, Abbastabar H, Abd-Allah F, et al. Global age-sex-specific fertility, mortality, healthy life expectancy (HALE), and population estimates in 204 countries and territories, 1950-2019: a comprehensive demographic analysis for the Global Burden of Disease Study 2019. The Lancet. 2020;396:1160-203.

2. United Nations Population Fund. \#GirlsNotMoms: Eliminating Teenage Pregnancy in the Philippines [Internet]. 2020 [cited 2021 Mar 22]. Available from: https://philippines.unfpa.org/sites/default/files/pub-pdf/UNFPA_Policy_Brief_Teenage_Pregnancy_\%282020-0124\%29.pdf

3. Frank TD, Carter A, Jahagirdar D, Biehl MH, Douwes-Schultz D, Larson SL, et al. Global, regional, and national incidence, prevalence, and mortality of HIV, 1980-2017, and forecasts to 2030, for 195 countries and territories: a systematic analysis for the Global Burden of Diseases, Injuries, and Risk Factors Study 2017. Lancet HIV. 2019;6:e831-59.

4. United Nations Population Fund, World Health Organization, Joint United Nations Program on HIV/AIDS. UNFPA, WHO and UNAIDS: Position statement on condoms and the prevention of HIV, other sexually transmitted infections and unintended pregnancy [Internet]. WHO. World Health Organization; 2015 [cited 2021 Mar 22]. Available from: https://www.who.int/hiv/mediacentre/news/condoms-jointpositionpaper/en/

5. Ajayi Al, Ismail KO, Akpan W. Factors associated with consistent condom use: a cross-sectional survey of two Nigerian universities. BMC Public Health. 2019;19:1207.

6. Philippine Statistics Authority (PSA), ICF. Philippine National Demographic and Health Survey 2017 [Internet]. PSA and ICF; 2018. Available from:

https://psa.gov.ph/sites/default/files/PHILIPPINE\%20NATIONAL\%20DEMOGRAPHIC\%20AND\%20HEALTH\%20SURVEY\%202017_new.pdf

7. De Torres RQ. Facilitators and barriers to condom use among Filipinos: A systematic review of literature. Health Promot Perspect. 2020;10:306-15.

8. Gangcuangco LMA, Tan ML, Berba RP. Prevalence and risk factors for HIV infection among men having sex with men in Metro Manila, Philippines. Southeast Asian J Trop Med Public Health. 2013;44:810-7.

9. Liu TI, So R. Knowledge, attitude, and preventive practice survey regarding AIDS comparing registered to freelance commercial sex workers in Iloilo City, Philippines. Southeast Asian J Trop Med Public Health. 1996;27:696-702.

10. Lucea MB, Hindin MJ, Gultiano S, Kub J, Rose L. The context of condom use among young adults in the Philippines: Implications for HIV prevention. Health Care Women Int. 2013;34:227-48.

11. Restar AJ, Adia A, Nazareno J, Hernandez L, Sandfort T, Lurie M, et al. Barriers and Facilitators to Uptake of Condoms among Filipinx Transgender Women and Cisgender Men who have sex with Men: A Situated Socio-Ecological Perspective. Glob Public Health. 2020;15:520-31.

12. Regan R, Morisky DE. Perceptions about HIV and condoms and consistent condom use among male clients of commercial sex workers in the Philippines. Health Educ Behav Off Publ Soc Public Health Educ. 2013;40:216-22.

13. Chiao C, Morisky DE, Ksobiech K, Malow RM. Promoting HIV Testing and Condom Use Among Filipina Commercial Sex Workers: Findings from a Quasi-Experimental Intervention Study. AIDS Behav. 2009;13:892-901.

14. Urada LA, Morisky DE, Hernandez LI, Strathdee SA. Social and Structural Factors Associated with Consistent Condom Use Among Female Entertainment Workers Trading Sex in the Philippines. AIDS Behav. 2013;17:523-35.

15. Amadora-Nolasco F, Alburo RE, Aguilar EJT, Trevathan WR. Knowledge, Perception of Risk for HIV, and Condom Use: A Comparison of Registered and Freelance Female Sex Workers in Cebu City, Philippines. AIDS Behav. 2001;5:319-30.

16. Morisky DE, Tiglao TV, Sneed CD, Tempongko SB, Baltazar JC, Detels R, et al. The effects of establishment practices, knowledge and attitudes on condom use among Filipina sex workers. AIDS Care. 1998;10:213-20.

17. Morisky DE, Peña M, Tiglao TV, Liu KY. The impact of the work environment on condom use among female bar workers in the Philippines. Health Educ Behav Off Publ Soc Public Health Educ. 2002;29:461-72. 
18. Aplasca MR, Siegel D, Mandel JS, Santana-Arciaga RT, Paul J, Hudes ES, et al. Results of a model AIDS prevention program for high school students in the Philippines. AIDS Lond Engl. 1995;9 Suppl 1:S7-13.

19. Regan R, Dyer TP, Gooding T, Morisky DE. Associations between drug use and sexual risks among heterosexual men in the Philippines. Int J STD AIDS. 2013;24:969-76.

20. Amit JML, Jimenez SJA, Magno CJCO, Andaya ARY, Saniel OP. Knowledge, Attitudes, Sexual Behaviors and Utilization of Health Services among Filipino Men who have Sex with Men (MSM). Acta Med Philipp [Internet]. 2015 [cited 2021 Mar 22];49. Available from: https://actamedicaphilippina.upm.edu.ph/index.php/acta/article/view/940

21. Urada LA, Morisky DE, Pimentel-Simbulan N, Silverman JG, Strathdee SA. Condom Negotiations among Female Sex Workers in the Philippines: Environmental Influences. PLoS ONE [Internet]. 2012 [cited 2021 Mar 22];7. Available from:

https://www.ncbi.nlm.nih.gov/pmc/articles/PMC3308968/

22. Guevara N, Pineda M, Dorotan M, Ghimire K, Co M, Guzman A, et al. Cross-sectional survey on the knowledge, attitude and practice of male Filipino seafarers on sexual health. Int Marit Health. 2010;62:224-32.

23. Morisky DE, Stein JA, Chiao C, Ksobiech K, Malow R. Impact of a Social Influence Intervention on Condom Use and Sexually Transmitted Infections Among Establishment-Based Female Sex Workers in the Philippines: A Multilevel Analysis. Health Psychol Off J Div Health Psychol Am Psychol Assoc. 2006;25:595-603.

24. Morisky DE, Malow RM, Tiglao TV, Lyu S-Y, Vissman AT, Rhodes SD. Reducing sexual risk among Filipina female bar workers: Effects of a CBPR-developed structural and network intervention. AIDS Educ Prev Off Publ Int Soc AIDS Educ. 2010;22:371-85.

25. Morisky DE, Stein JA, Sneed CD, Tiglao TV, Liu K, Detels R, et al. Modeling Personal and Situational Influences on Condom Use Among Establishment-Based Commercial Sex Workers in the Philippines. AIDS Behav. 2002;6:163-72.

26. Nishimura-Takahashi T, Akabayashi A, Kai I, Cabigon J, Ohi G, Naka K. Social and behavioral factors associated with condom use among female commercial sex workers (CSWs) in tarlac, the Philippines. Environ Health Prev Med. 1998;2:167-71.

27. Morisky DE, Ang A, Coly A, Tiglao TV. A model HIV/AIDS risk reduction programme in the Philippines: a comprehensive communitybased approach through participatory action research. Health Promot Int. 2004;19:69-76.

28. Morisky DE, Nguyen C, Ang A, Tiglao TV. HIV/AIDS Prevention Among the Male Population: Results of a Peer Education Program for Taxicab and Tricycle Drivers in the Philippines. Health Educ Behav Off Publ Soc Public Health Educ. 2005;32:57-68.

29. Morisky DE, Tiglao TV. Educational and Structural Interventions and Their Impact on Condom Use and STI/HIV Prevention for Filipina Women and Male Customers. Asia-Pac J Public Health Asia-Pac Acad Consort Public Health. 2010;22:151S-158S.

30. Republic Act No. 10354 [Internet]. Off. Gaz. Repub. Philipp. 2012 [cited 2021 Mar 21]. Available from:

https://www.officialgazette.gov.ph/2012/12/21/republic-act-no-10354/

31. Executive Order No. 12, s. 2017 [Internet]. Off. Gaz. Repub. Philipp. 2017 [cited 2021 Mar 21]. Available from: https://www.officialgazette.gov.ph/2017/01/09/executive-order-no-12-s-2017/

32. Chen B, Chen J, Shao Y, Hu D, Ding X, Wen Y. Need for Intervention Services for Promotion of Condom Use by Female Sex Workers to Consider Size of Entertainment Venues: A Cross-Sectional Study. Med Sci Monit Basic Res. 2019;25:1-7.

33. Liu Z, Wei P, Huang M, Liu Y bao, Li L, Gong X, et al. Determinants of Consistent Condom Use among College Students in China: Application of the Information-Motivation-Behavior Skills (IMB) Model. PLOS ONE. Public Library of Science; 2014;9:e108976.

34. Ye X, Shang M, Shen T, Pei B, Jiang X, Cai Y. Social, psychological, and environmental-structural factors determine consistent condom use among rural-to-urban migrant female sex workers in Shanghai China. BMC Public Health. 2012;12:599.

35. Ali MS, Tesfaye Tegegne E, Kassa Tesemma M, Tesfaye Tegegne K. Consistent Condom Use and Associated Factors among HIVPositive Clients on Antiretroviral Therapy in North West Ethiopian Health Center, 2016 GC. AIDS Res Treat. Hindawi;

2019;2019:e7134908.

Page 9/17 
36. Yoshioka E, Palatino M, Nazareno J, Operario D. Intimate Partner Violence and Sexual Agency in a Nationally Representative Sample of Women and Girls in the Philippines. J Interpers Violence. SAGE Publications Inc; 2020;0886260520976208.

37. StataCorp. Stata 14.0 IC. College Station, TX: StataCorp; 2015.

38. Rothman KJ. No adjustments are needed for multiple comparisons. Epidemiol Camb Mass. 1990;1:43-6.

39. Cense M. Rethinking sexual agency: proposing a multicomponent model based on young people's life stories. Sex Educ. Routledge; 2019;19:247-62.

40. Delgado-Infante ML, Ofreneo MAP. Maintaining a "good girl" position: Young Filipina women constructing sexual agency in first sex within Catholicism. Fem Psychol. 2014;24:390-407.

41. Cabral E. Reproductive Health Law in the Philippines. J ASEAN Fed Endocr Soc. 2013;28:26-26.

42. Bay-Cheng LY. Agency Is Everywhere, but Agency Is Not Enough: A Conceptual Analysis of Young Women's Sexual Agency. J Sex Res. Taylor \& Francis; 2019;56:462-74.

43. Ajayi Al, Adeniyi OV, Akpan W. Use of traditional and modern contraceptives among childbearing women: findings from a mixed methods study in two southwestern Nigerian states. BMC Public Health. 2018;18:604.

44. Higgins JA, Hirsch JS. Pleasure, Power, and Inequality: Incorporating Sexuality Into Research on Contraceptive Use. Am J Public Health. 2008;98:1803-13.

45. Widman L, Golin CE, Noar SM. When do condom use intentions lead to actions? Examining the role of sexual communication on safer sexual behavior among people living with HIV. J Health Psychol. 2013;18:507-17.

\section{Tables}

Table 1. Cross-tabulations of categorical exposure variables with consistent condom use $(n=25,074)$. 


\begin{tabular}{|c|c|c|c|c|c|c|}
\hline & $\begin{array}{l}\text { Inconsistent } \\
\text { condom use (0) }\end{array}$ & $\begin{array}{l}\text { Consistent } \\
\text { condom use (1) }\end{array}$ & Missing & $\begin{array}{l}\mathrm{p} \text { - } \\
\text { value }\end{array}$ & $\begin{array}{l}\text { Crude } \\
\text { OR } \\
\text { (with } \\
95 \% \\
\mathrm{Cl} \text { ) }\end{array}$ & $\begin{array}{l}\mathrm{p}- \\
\text { value } \\
\text { of OR }\end{array}$ \\
\hline \multicolumn{7}{|c|}{ Educational attainment of respondent } \\
\hline \multirow[t]{2}{*}{ No education } & 236 & 0 & 77 & \multirow{8}{*}{$<.01$} & - & \\
\hline & $(73.87 \%)$ & $(0.00 \%)$ & $(26.13 \%)$ & & & \\
\hline \multirow[t]{2}{*}{ Primary education } & 3,041 & 27 & 785 & & 0.36 & $<0.01$ \\
\hline & $(77.77 \%)$ & $(0.84 \%)$ & $(21.39 \%)$ & & $\begin{array}{l}(0.20 \\
0.63)\end{array}$ & \\
\hline \multirow[t]{2}{*}{ Secondary education } & 7,164 & 102 & 5,153 & & 0.51 & $<0.01$ \\
\hline & $(57.89 \%)$ & $(0.88 \%)$ & $(41.23 \%)$ & & $\begin{array}{l}(0.35 \\
0.73)\end{array}$ & \\
\hline \multirow[t]{2}{*}{ Higher } & 4,694 & 132 & 3,662 & & 1 & \\
\hline & $(53.37 \%)$ & $(1.60 \%)$ & $(45.03 \%)$ & & & \\
\hline \multirow[t]{2}{*}{ Missing } & 0 & 0 & 1 & & & \\
\hline & $(0.00 \%)$ & $(0.00 \%)$ & $(100 \%)$ & & & \\
\hline \multicolumn{7}{|c|}{ Employment (Respondent currently working) } \\
\hline \multirow[t]{2}{*}{ No } & 7,449 & 112 & 6,138 & 0.28 & 1 & \\
\hline & $(54.72 \%)$ & $(0.95 \%)$ & $(44.34 \%)$ & & & \\
\hline \multirow[t]{2}{*}{ Yes } & 7,686 & 149 & 3,540 & & 1.21 & 0.28 \\
\hline & $(63.86 \%)$ & $(1.34 \%)$ & $(34.80 \%)$ & & $\begin{array}{l}(0.86 \\
1.72)\end{array}$ & \\
\hline \multicolumn{7}{|l|}{ Alcohol consumption } \\
\hline \multirow[t]{2}{*}{ No } & 11,185 & 168 & 7,543 & 0.06 & 1 & \\
\hline & $(57.83 \%)$ & $(0.99 \%)$ & $(41.18 \%)$ & & & \\
\hline \multirow[t]{2}{*}{ Yes } & 3,950 & 93 & 2,135 & & 1.43 & 0.07 \\
\hline & $(62.09 \%)$ & $(1.53 \%)$ & $(36.38 \%)$ & & $\begin{array}{l}(0.98 \\
2.10)\end{array}$ & \\
\hline \multicolumn{7}{|l|}{ Wealth index } \\
\hline \multirow[t]{2}{*}{ Poorest } & 4,156 & 42 & 1,733 & 0.01 & 1 & \\
\hline & $(70.56 \%)$ & $(0.62 \%)$ & $(28.82 \%)$ & & & \\
\hline \multirow[t]{2}{*}{ Poorer } & 3,494 & 50 & 1,947 & & 2.06 & 0.01 \\
\hline & $(64.66 \%)$ & $(1.17 \%)$ & $(34.18 \%)$ & & $\begin{array}{l}(1.17 \\
3.64)\end{array}$ & \\
\hline \multirow[t]{2}{*}{ Middle } & 2,924 & 49 & 1,883 & & 2.17 & $<0.01$ \\
\hline & $(61.62 \%)$ & $(1.17 \%)$ & $(37.21 \%)$ & & $\begin{array}{l}(1.28, \\
3.69)\end{array}$ & \\
\hline \multirow[t]{2}{*}{ Richer } & 2,492 & 62 & 2,021 & & 2.54 & $<0.01$ \\
\hline & $(54.16 \%)$ & $(1.21 \%)$ & $(44.63 \%)$ & & $\begin{array}{l}(1.53 \\
4.24)\end{array}$ & \\
\hline \multirow[t]{2}{*}{ Richest } & 2,069 & 58 & 2,094 & & 3.22 & $<0.01$ \\
\hline & $(48.22 \%)$ & $(1.36 \%)$ & $(50.41 \%)$ & & & \\
\hline
\end{tabular}


Current marital status

\begin{tabular}{|c|c|c|c|c|c|c|}
\hline \multirow[t]{2}{*}{ Never in union } & 480 & 46 & 8,126 & \multirow{2}{*}{$<.01$} & \multirow[t]{2}{*}{1} & \\
\hline & $(5.93 \%)$ & $(0.55 \%)$ & $(93.52 \%)$ & & & \\
\hline \multirow[t]{2}{*}{ Married } & 10,665 & 170 & 623 & & 0.18 & $<0.01$ \\
\hline & $(92.64 \%)$ & $(1.55 \%)$ & $(5.81 \%)$ & & $\begin{array}{l}(0.11, \\
0.28)\end{array}$ & \\
\hline \multirow[t]{2}{*}{ Living with partner } & 3,779 & 35 & 173 & & 0.13 & $<0.01$ \\
\hline & $(94.94 \%)$ & $(1.19 \%)$ & $(3.86 \%)$ & & $\begin{array}{l}(0.06 \\
0.30)\end{array}$ & \\
\hline \multirow{2}{*}{$\begin{array}{l}\text { Widowed/Divorced/No longer living together } \\
\text { or separated }\end{array}$} & 211 & 10 & 756 & & 0.79 & 0.61 \\
\hline & $(21.60 \%)$ & $(1.58 \%)$ & $(76.82 \%)$ & & $\begin{array}{l}(0.31 \\
1.98)\end{array}$ & \\
\hline
\end{tabular}

Ever been tested for HIV

No

14,573

245

(58.35\%)

562

(71.27\%)

Yes

Tobacco use

Does not use tobacco

Uses tobacco

14,306

(58.54\%)

829

(66.06\%)
(1.07\%)

16

$(2.41 \%)$
9,457

$(40.58 \%)$

221

(26.32\%)

$0.24 \quad 1$

1.84

$(0.66$, 5.15)

\begin{tabular}{|c|c|c|c|c|c|c|}
\hline & $(58.54 \%)$ & $(1.11 \%)$ & $(40.35 \%)$ & & & \\
\hline \multirow[t]{2}{*}{ Uses tobacco } & 829 & 15 & 334 & & 1.20 & 0.59 \\
\hline & $(66.06 \%)$ & $(1.50 \%)$ & $(32.44 \%)$ & & $\begin{array}{l}(0.63 \\
2.29)\end{array}$ & \\
\hline \multicolumn{7}{|l|}{ Contraceptive use and intention } \\
\hline \multirow[t]{2}{*}{ Does not intend to use } & 4,749 & 10 & 5,809 & \multirow{8}{*}{$\begin{array}{l}< \\
0.01\end{array}$} & 1 & \\
\hline & $(43.11 \%)$ & $(0.01 \%)$ & $(56.84 \%)$ & & & \\
\hline \multirow[t]{2}{*}{ Non-user intends to use later } & 2,456 & 38 & 3,580 & & 15.02 & $<0.01$ \\
\hline & $(38.57 \%)$ & $(0.74 \%)$ & $(60.70 \%)$ & & $\begin{array}{l}(6.75 \\
33.42)\end{array}$ & \\
\hline \multirow[t]{2}{*}{ Using traditional method } & 1,905 & 4 & 49 & & 2.52 & 0.29 \\
\hline & $(97.68 \%)$ & $(0.31 \%)$ & $(2.01 \%)$ & & $\begin{array}{l}(0.46 \\
13.80)\end{array}$ & \\
\hline \multirow[t]{2}{*}{ Using modern method } & 6,025 & 209 & 240 & & 30.81 & $<0.01$ \\
\hline & $(92.12 \%)$ & $(3.61 \%)$ & $(4.27 \%)$ & & $\begin{array}{l}(14.61 \\
64.97)\end{array}$ & \\
\hline \multicolumn{7}{|l|}{ Religion } \\
\hline \multirow[t]{2}{*}{ Roman catholic } & 10,977 & 199 & 6,965 & 0.17 & 1 & \\
\hline & $(58.89 \%)$ & $(1.19 \%)$ & $(39.92 \%)$ & & & \\
\hline \multirow[t]{2}{*}{ Protestant } & 1,413 & 33 & 868 & & 1.15 & 0.57 \\
\hline & $(58.65 \%)$ & $(1.36 \%)$ & $(39.99 \%)$ & & $\begin{array}{l}(0.71 \\
1.85)\end{array}$ & \\
\hline
\end{tabular}




\begin{tabular}{|c|c|c|c|c|c|c|}
\hline \multirow[t]{2}{*}{ Iglesia ni Cristo } & 434 & 6 & 286 & & 0.77 & 0.61 \\
\hline & $(58.24 \%)$ & $(0.90 \%)$ & $(40.86 \%)$ & & $\begin{array}{l}(0.28 \\
2.13)\end{array}$ & \\
\hline \multirow[t]{2}{*}{ Aglipay } & 208 & 0 & 127 & & - & \\
\hline & $(62.65 \%)$ & $(0.00 \%)$ & $(37.35 \%)$ & & & \\
\hline \multirow[t]{2}{*}{ Islam } & 1,309 & 6 & 1,006 & & 0.29 & 0.02 \\
\hline & $(57.84 \%)$ & $(0.34 \%)$ & $(41.82 \%)$ & & $\begin{array}{l}(0.11 \\
0.78)\end{array}$ & \\
\hline \multirow[t]{2}{*}{ Other Christian } & 474 & 14 & 295 & & 0.97 & 0.93 \\
\hline & $(58.16 \%)$ & $(1.14 \%)$ & $(40.70 \%)$ & & $\begin{array}{l}(0.50 \\
1.87)^{\prime}\end{array}$ & \\
\hline \multirow[t]{2}{*}{ Other/None } & 320 & 3 & 131 & & 0.40 & 0.16 \\
\hline & $(68.47 \%)$ & $(0.55 \%)$ & $(30.98 \%)$ & & $\begin{array}{l}(0.11 \\
1.46)^{\prime}\end{array}$ & \\
\hline \multicolumn{7}{|c|}{ Educational attainment of partner } \\
\hline \multirow[t]{2}{*}{ No education } & 265 & 0 & 14 & 0.06 & - & \\
\hline & $(92.99 \%)$ & $(0.00 \%)$ & $(7.01 \%)$ & & & \\
\hline \multirow[t]{2}{*}{ Primary education } & 4,158 & 35 & 182 & & 0.52 & 0.05 \\
\hline & $(94.22 \%)$ & $(1.07 \%)$ & $(4.71 \%)$ & & $\begin{array}{l}(0.28 \\
0.99)\end{array}$ & \\
\hline \multirow[t]{2}{*}{ Secondary education } & 6,000 & 85 & 300 & & 0.63 & 0.05 \\
\hline & $(94.30 \%)$ & $(1.29 \%)$ & $(4.40 \%)$ & & $\begin{array}{l}(0.40 \\
1.00)\end{array}$ & \\
\hline \multirow[t]{2}{*}{ Higher } & 4,013 & 85 & 300 & & 1 & \\
\hline & $(91.30 \%)$ & $(1.98 \%)$ & $(6.72 \%)$ & & & \\
\hline \multirow[t]{2}{*}{ Missing } & 699 & 56 & 8,882 & & & \\
\hline & $(7.68 \%)$ & $(0.66 \%)$ & $(91.65 \%)$ & & & \\
\hline \multicolumn{7}{|c|}{$\begin{array}{l}\text { Wife justified asking husband to use condom } \\
\text { if he has an STI }\end{array}$} \\
\hline \multirow[t]{2}{*}{ No } & 2,308 & 23 & 2,461 & 0.03 & 1 & \\
\hline & $(47.35 \%)$ & $(0.56 \%)$ & $(52.09 \%)$ & & & \\
\hline \multirow[t]{2}{*}{ Yes } & 12,827 & 238 & 7,217 & & 1.72 & 0.04 \\
\hline & $(61.40 \%)$ & $(1.25 \%)$ & $(37.34 \%)$ & & $\begin{array}{l}(1.04 \\
2.85)\end{array}$ & \\
\hline \multicolumn{7}{|c|}{ Respondent can ask partner to use a condom } \\
\hline \multirow[t]{2}{*}{ No } & 3,893 & 7 & 198 & $<$ & 1 & \\
\hline & (95.12\%) & $(0.25 \%)$ & (4.63\%) & & & \\
\hline \multirow[t]{2}{*}{ Yes } & 10,551 & 198 & 598 & & 7.62 & $<0.01$ \\
\hline & (92.72\%) & $(1.84 \%)$ & $(5.44 \%)$ & & $\begin{array}{l}(2.45 \\
23.70)\end{array}$ & \\
\hline \multirow[t]{2}{*}{ Missing } & 691 & 56 & 8,882 & & & \\
\hline & $(7.62 \%)$ & $(0.66 \%)$ & (91.71\%) & & & \\
\hline
\end{tabular}




\begin{tabular}{|c|c|c|c|c|c|c|}
\hline \multirow[t]{2}{*}{ Mainly respondent } & 1,043 & 5 & & \multirow[t]{2}{*}{0.74} & \multicolumn{2}{|l|}{1} \\
\hline & (95.09\%) & $(1.57 \%)$ & $(3.35 \%)$ & & & \\
\hline \multirow[t]{2}{*}{ Mainly husband/partner } & 494 & 14 & 6 & & 2.17 & 0.37 \\
\hline & $(95.25 \%)$ & $(3.41 \%)$ & $(1.34 \%)$ & & $\begin{array}{l}(0.41 \\
11.59)\end{array}$ & \\
\hline \multirow[t]{2}{*}{ Joint decision } & 6,219 & 168 & 175 & & 1.66 & 0.52 \\
\hline & $(94.71 \%)$ & $(2.59 \%)$ & $(2.70 \%)$ & & $\begin{array}{l}(0.35 \\
7.83)\end{array}$ & \\
\hline \multirow[t]{2}{*}{ Other } & 32 & 0 & 2 & & 1 & \\
\hline & $(93.36 \%)$ & $(0.00 \%)$ & $(6.64 \%)$ & & & \\
\hline \multirow[t]{2}{*}{ Missing } & 7,347 & 74 & 9,454 & & & \\
\hline & $(41.69 \%)$ & $(0.48 \%)$ & $(57.83 \%)$ & & & \\
\hline \multicolumn{7}{|c|}{$\begin{array}{l}\text { Read information about contraception on the } \\
\text { internet }\end{array}$} \\
\hline \multirow[t]{2}{*}{ No } & 11,198 & 157 & 5,672 & \multirow{4}{*}{$<.01$} & 1 & \\
\hline & $(\%)$ & $(\%)$ & $(\%)$ & & & \\
\hline \multirow[t]{2}{*}{ Yes } & 3,937 & 104 & 4,006 & & 1.65 & 0.01 \\
\hline & $(\%)$ & $(\%)$ & $(\%)$ & & $\begin{array}{l}(1.12, \\
2.41)\end{array}$ & \\
\hline \multicolumn{7}{|c|}{$\begin{array}{l}\text { Heard family planning on radio last few } \\
\text { months }\end{array}$} \\
\hline \multirow[t]{2}{*}{ No } & 9,181 & 168 & 6,846 & 0.72 & 1 & \\
\hline & $(55.86 \%)$ & $(1.10 \%)$ & $(43.03 \%)$ & & & \\
\hline \multirow[t]{2}{*}{ Yes } & 5,954 & 93 & 2,832 & & 0.92 & 0.72 \\
\hline & $(64.93 \%)$ & $(1.18 \%)$ & $(33.89 \%)$ & & $\begin{array}{l}(0.60 \\
1.41)\end{array}$ & \\
\hline \multicolumn{7}{|c|}{$\begin{array}{l}\text { Heard family planning on television last few } \\
\text { months }\end{array}$} \\
\hline \multirow[t]{2}{*}{ No } & 5,724 & 73 & 4,156 & 0.04 & 1 & \\
\hline & (56.58\%) & $(0.84 \%)$ & (42.58\%) & & & \\
\hline \multirow[t]{2}{*}{ Yes } & 9,411 & 188 & 5,522 & & 1.46 & 0.04 \\
\hline & $(60.37 \%)$ & $(1.31 \%)$ & (38.32\%) & & $\begin{array}{l}(1.02, \\
2.10)\end{array}$ & \\
\hline \multicolumn{7}{|c|}{$\begin{array}{l}\text { Heard family planning in } \\
\text { newspaper/magazine last few months }\end{array}$} \\
\hline \multirow[t]{2}{*}{ No } & 12,502 & 206 & 8,031 & 0.21 & 1 & \\
\hline & (58.77\%) & (1.05\%) & $(40.18 \%)$ & & & \\
\hline \multirow[t]{2}{*}{ Yes } & 2,633 & 55 & 1,647 & & 1.37 & 0.22 \\
\hline & (59.62\%) & $(1.46 \%)$ & (38.92\%) & & $\begin{array}{l}(0.83 \\
2.25)\end{array}$ & \\
\hline \multicolumn{7}{|c|}{$\begin{array}{l}\text { Heard family planning by test messages on } \\
\text { mobile phone }\end{array}$} \\
\hline \multirow[t]{2}{*}{ No } & 14,243 & 240 & 9,101 & 0.91 & 1 & \\
\hline & (59.11\%) & $(1.14 \%)$ & $(39.75 \%)$ & & & \\
\hline
\end{tabular}




\begin{tabular}{|c|c|c|c|c|c|c|}
\hline Yes & $\begin{array}{l}892 \\
(56.46 \%)\end{array}$ & $\begin{array}{l}21 \\
(1.05 \%)\end{array}$ & $\begin{array}{l}577 \\
(42.49 \%)\end{array}$ & & $\begin{array}{l}0.97 \\
(0.53, \\
1.75)\end{array}$ & 0.91 \\
\hline \multicolumn{7}{|c|}{ Domicile (Type of place of residence) } \\
\hline \multirow[t]{2}{*}{ Urban } & 5,062 & 114 & 3,840 & \multirow[t]{4}{*}{0.06} & \multirow[t]{2}{*}{1} & \\
\hline & $(55.23 \%)$ & $(1.26 \%)$ & $(43.51 \%)$ & & & \\
\hline \multirow[t]{2}{*}{ Rural } & 10,073 & 147 & 5,838 & & 0.71 & \multirow[t]{2}{*}{0.07} \\
\hline & $(62.49 \%)$ & $(1.01 \%)$ & $(36.50 \%)$ & & $\begin{array}{l}(0.49 \\
1.02)\end{array}$ & \\
\hline
\end{tabular}

Table 2. Continuous variables and their association with consistent condom use.

\begin{tabular}{|c|c|c|c|c|c|c|c|}
\hline & Range & Mean & Median & Distribution & $\begin{array}{l}\text { p-value of rank sum } \\
\text { test }\end{array}$ & $\begin{array}{l}\text { Crude OR } \\
\text { (with 95\% } \\
\mathrm{Cl} \text { ) }\end{array}$ & $\begin{array}{l}\text { p-value of } \\
\text { OR }\end{array}$ \\
\hline HIV knowledge $(n=22,813)$ & $0-8$ & 5.18 & 5 & $\begin{array}{l}\text { Left- } \\
\text { skewed }\end{array}$ & $<0.01$ & $\begin{array}{l}1.23 \\
(1.06,1.42)\end{array}$ & $<0.01$ \\
\hline Age of respondent $(n=25,074)$ & $\begin{array}{l}15- \\
49\end{array}$ & 30.14 & 29 & $\begin{array}{l}\text { Right- } \\
\text { skewed }\end{array}$ & 0.03 & $\begin{array}{l}0.98 \\
(0.96,0.99)\end{array}$ & 0.01 \\
\hline $\begin{array}{l}\text { Age of most recent partner } \\
(n=15,378)\end{array}$ & $\begin{array}{l}10- \\
95\end{array}$ & 37.14 & 37 & $\begin{array}{l}\text { Right- } \\
\text { skewed }\end{array}$ & 0.02 & $\begin{array}{l}0.98 \\
(0.96,1.00)\end{array}$ & 0.02 \\
\hline $\begin{array}{l}\text { Total lifetime number of sex } \\
\text { partners } \\
(n=17,701)\end{array}$ & $1-95$ & 1.40 & 1 & $\begin{array}{l}\text { Right- } \\
\text { skewed }\end{array}$ & 0.21 & $\begin{array}{l}0.99 \\
(0.97,1.01)\end{array}$ & 0.43 \\
\hline $\begin{array}{l}\text { Household size } \\
(n-25,074)\end{array}$ & $1-21$ & 5.39 & 5 & $\begin{array}{l}\text { Right- } \\
\text { Skewed }\end{array}$ & 0.39 & $\begin{array}{l}1.02 \\
(0.93,1.12)\end{array}$ & 0.65 \\
\hline $\begin{array}{l}\text { Total children ever born } \\
(n=25,074)\end{array}$ & $0-18$ & 1.77 & 1 & $\begin{array}{l}\text { Right- } \\
\text { Skewed }\end{array}$ & $<0.01$ & $\begin{array}{l}0.88 \\
(0.81,0.97)\end{array}$ & $<0.01$ \\
\hline
\end{tabular}

Table 3. Association of selected socio-demographic and sexual health variables with consistent condom use $(n=13,283)$. 
Educational attainment of respondent

Primary education

1

Secondary education

$0.86(0.43,1.69)$

0.66

Higher

$1.51(0.76,3.02)$

0.23

Civil Status

Married

1

Living with partner

$0.87(0.42,1.83)$

0.72

Wealth index

Poorest

1

Poorer

$1.42(0.73,2.77)$

0.30

Middle class

$1.44(0.74,2.82)$

0.29

Richer

$1.44(0.73,2.85)$

0.30

Richest

$1.30(0.58,2.91)$

0.52

Age (common odds ratio)

$1.02(0.99,1.05)$

0.26

Alcohol consumption

No

1

Yes

Respondent currently working

No

1

Yes

Contraceptive use and intention

Do not intend to use any form of contraception 1

Current non-users but intends to use contraception later

Users of traditional contraceptive methods

$(2.41,33.18)$

Users of modern contraceptive methods (including male/female condom)

$1.04(0.20,5.37)$

0.96

59.67

$(21.13,168.47)$

Respondent can ask partner to use condom

No

1

Yes

$6.31(2.08,19.16)$

$<0.01$

Reading about contraception on the internet

No

1

Yes

$1.18(0.78,1.80)$

0.43

HIV knowledge score (common odds ratio)

$1.17(0.98,1.39)$

0.08

Number of children (common odds ratio)

$0.92(0.79,1.06)$

0.22

Respondent believes that it is justified for the wife to ask husband to use condom if he has STI 
Hearing about contraception on television

No

1

Yes 